\title{
Histomorphometric Evaluation of Anorganic Bovine Bone Coverage to Reduce Autogenous Grafts Resorption: Preliminary Results
}

\author{
Carlo Maiorana ${ }^{1}$, Mario Beretta ${ }^{1}$, Giovanni Battista Grossi ${ }^{1}$, Franco Santoro ${ }^{1}$, Alan Scott \\ Herford $^{2}$, Heiner Nagursky ${ }^{3}$ and Marco Cicciù ${ }^{4}$, \\ ${ }^{I}$ Oral Surgery and Implantology, University of Milan, School of Dentistry, IRCSS Cà Granda, Milan, Italy \\ ${ }^{2}$ Oral and Maxillofacial Surgery Department, Loma Linda University, Loma Linda, California US \\ ${ }^{3}$ Hard Tissue Research Laboratory, Department for Oral- and Maxillofacial Surgery, University Hospital Freiburg, \\ Freiburg, Germany \\ ${ }^{4}$ Dental Clinic, University of Messina, School of Dentistry, Italy
}

\begin{abstract}
Physiologic resorption due to remodeling processes affects autogenous corticocancellous grafts in the treatment of atrophic jawbone alveolar ridges. Such a situation in the past made overgrafting of the recipient site mandatory to get enough bone support to dental implants in order to perform a prosthetic rehabilitation. Anorganic bovine bone, conventionally used to treat alveolar bone deficiencies in implant surgery, showed a high osteoconductive property thanks to its micro and macrostructure very similar to that of human hydroxyapatite. An original technique provides for the application of a thin layer of anorganic bovine bone granules and a collagen membrane on the top of the corticocancellous onlay bone grafts to reduce in a remarkable way the graft resorption due to remodeling. The results of a clinical prospective study and a histomorphometric analysis done on autogenous grafts harvested from the iliac crest showed that the proposed technique is able to maintain the original bone volume of the corticocancellous blocks.
\end{abstract}

Key Words: Bone graft, bone remodelling, bone regeneration.

\section{INTRODUCTION}

The successful use of osseointegrated implants in the treatment of partial or complete edentulism requires a sufficient bone support. Bone resorption takes place after tooth extraction, as a consequence of normal turnover process occurring in all bone and is affecting the alveolar ridge either on a vertical or horizontal plan, thus creating an overall reduction of the amount of bone available to dental implants. Whenever rehabilitation in edentulous areas is needed, bone augmentation procedures are available: bony reconstruction provides adjunctive support for implants, allowing prosthetically guided implant placement and improves the aesthetic result of the treatment. Bone grafting of the atrophic sites can be carried out, either prior to implant placement or at the time of implant placement $[1,2]$.

Bone augmentation using autografts is a reliable technique, as confirmed by several studies. Nevertheless in the first three months after grafting, the volume of the augmented area is diminished.

A variety of surgical techniques have been described to enhance bone volume of deficient implant-recipient sites, such as the use of onlay grafts, ridge splitting or bone condensation. The most common methods include grafting procedures, with or without coverage by a barrier membrane

*Address correspondence to this author at the Oral Surgery and Implantolgy, University of Milan School of Dentistry, Italy; Tel: 00390255032621 ; Fax: 00390255032513; E-mail: acromarco@yahoo.it (guided bone regeneration (GBR)). Horizontal ridge augmentation with autogenous block grafts, covered with bioinert expanded polytetrafluoroethylene (ePTFE) membrane, is well documented and results in a good clinical outcome [3, 4].

However, use of ePTFE membranes exhibit some disadvantages: handling and fixation of the hydrophobic membrane is difficult; incision and flap management are demanding, and the technique harbors a certain risk of wound dehiscence with membrane exposure and subsequent site infection $[5,6]$.

Therefore, clinicians and researchers started looking for alternative barrier membranes in the mid-1990s. Today, after more than 10 years of experimental and clinical experience, the application of bioabsorbable membranes - in particular, collagen membranes - appear to have overcome these problems $[7,8]$. However, barrier function and lifespan of resorbable membranes vary considerably and the barrier function is limited to only a few weeks $[9,10]$. In contrast, anorganic bovine bone has been shown to resist resorption, after placement into bony defects or as an onlay graft [11]. Therefore, this bone substitute seems to be appropriate to be combined with autogenous bone grafts and collagen membranes, which exhibit only limited barrier function.

Grafting techniques, type of surgery, soft tissue pressure and muscle function, amount of revascularization and some genetic parameters can influence bone resorption [12-16]. Graft overextension is not an appropriate prophylactic measure to limit resorption. 


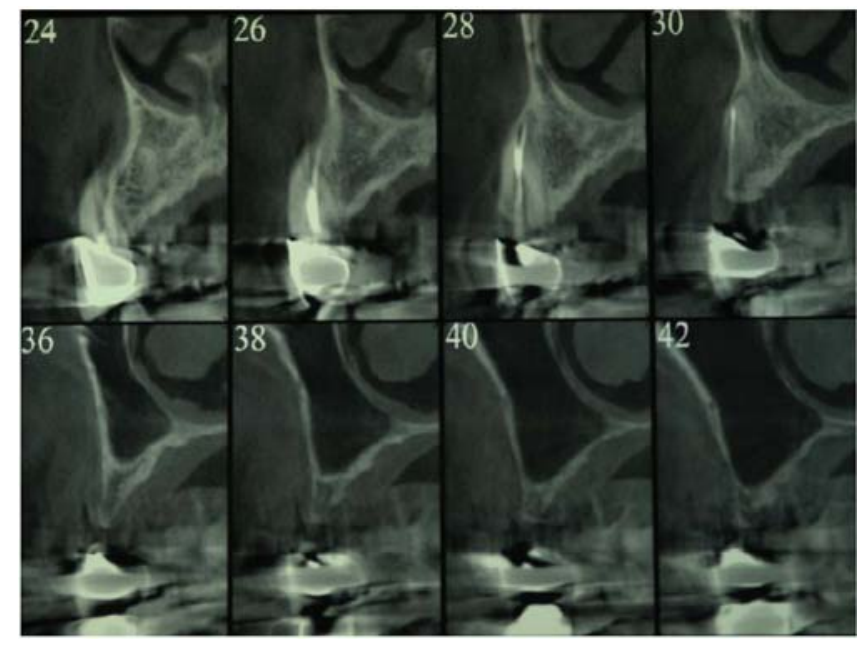

Fig. (1). Radiographic representation of an atrophic maxilla class VI Cawood Howell.

The more the grafted area is over-extended, the greater is the occurring resorption. Resorption also depends on the position of the graft area, for example, the anterior region of the mandible presents a higher rate of resorption compared to the posterior area of the maxilla [16].

In 2005 Maiorana et al. [17] established a procedure to reduce resorption of autogenous corticocancellous bone by using anorganic bovine bone matrix granules (Bio-Oss®, Geistlich Pharma, Wolhusen, Switzerland), spread on top of bone blocks and kept in place by use of porcine collagen membranes (Bio-Gide ${ }^{\circledR}$ Geistlich Pharma,Wolhusen, Switzerland), thereby reducing graft resorption up to $50 \%$.

During Bio-Oss production, the organic scaffold of bovine bone is removed leaving intercrystalline microtunnels and microcapillaries between apatite crystals. The remaining mineral matrix is similar to that of human bone, in terms of chemical composition, morphology and ultrastructure [18, 19].

Aim of this publication is to examine, by histomorphometric evaluation, the resorption - inhibitory effect of anorganic bovine bone, planted onto corticocancellous blocks in a split jaw experiment.

\section{MATERIALS AND METHODOLOGY}

The study was performed with 12 adults, with mean age 55 years, affected by class V or VI maxillary atrophy according to Cawood and Howell with a 2 or $3 \mathrm{~mm}$ of residual horizontal ridge; the bone hardness of each patients could be associated to the grade $3-4$ according to the Misch and Judy classification [20, 21] (Figs. 1, 2).

The treatment plan provided for onlay corticocancellous grafts harvested from the hip, under general anesthesia (Fig. 3).

Surgeries were performed in the surgical unit, Policlinico General Hospital Foundation, University of Milan, Italy. Onlay grafts, the grafts were modeled and adapted to the atrophic ridge and secured to the recipient site with transcortical screws (Fig. 4).

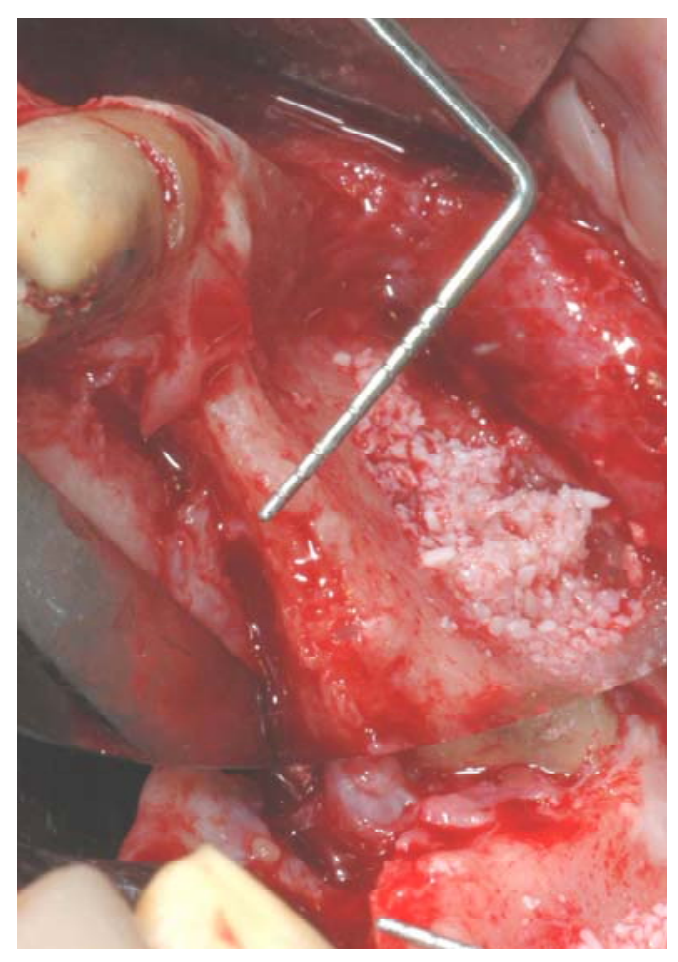

Fig. (2). Clinical image of the large bone defect. The probe show how thin is the residual ridge.

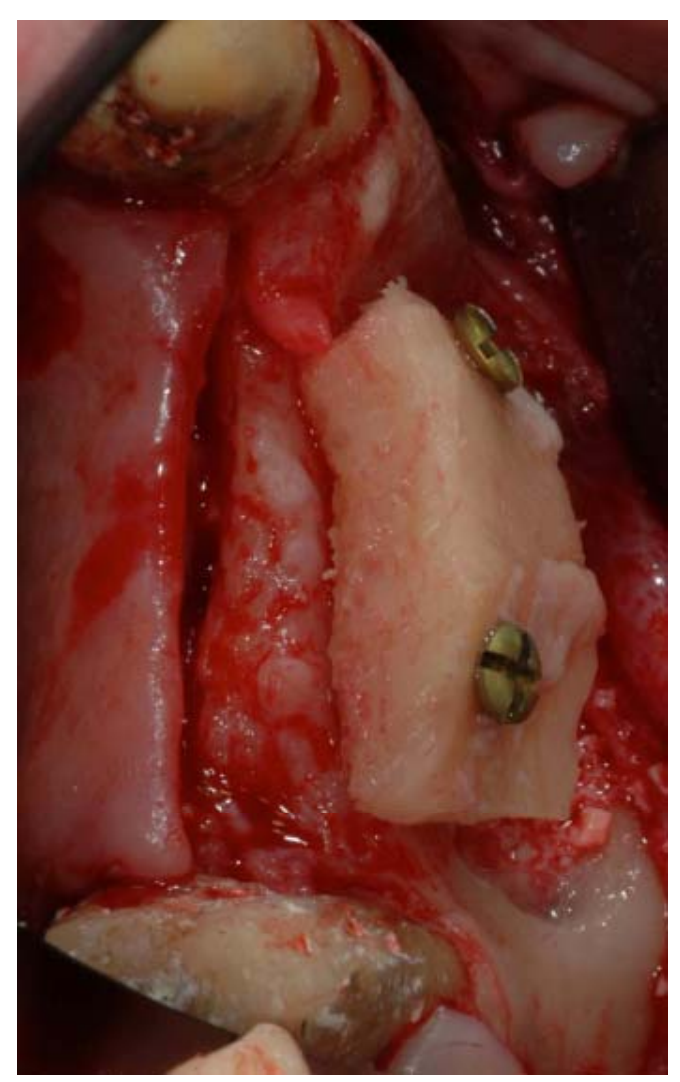

Fig. (3). Two screws fixed iliac onlay bone graft for ridge augmentation.

During the intervention, measurements of the alveolar ridge width and height were done prior to graft placement 


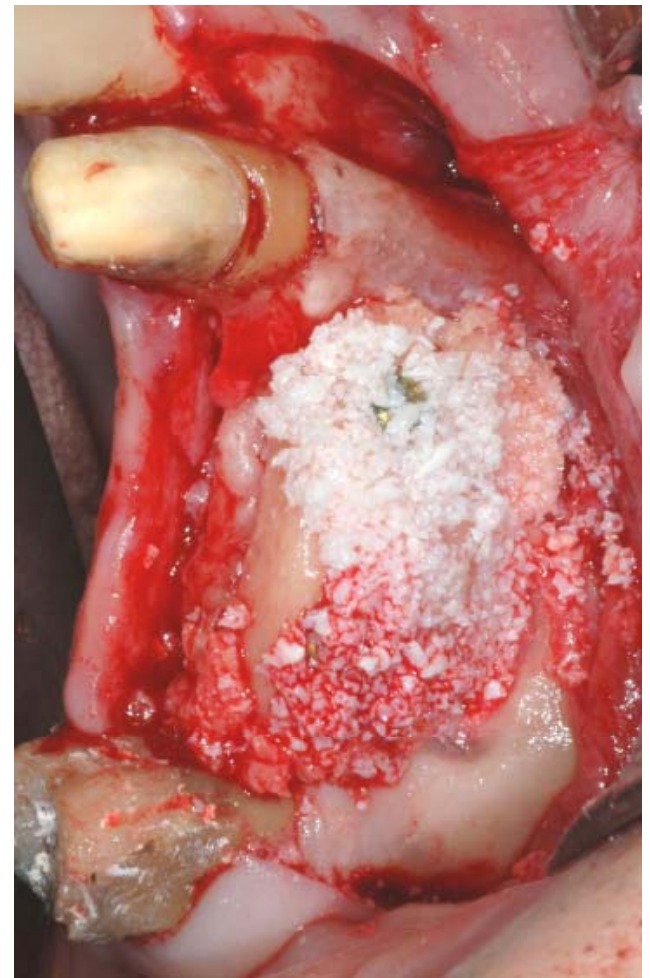

Fig. (4). Deproteinized bovine bone was then applied to cover the bone graft.

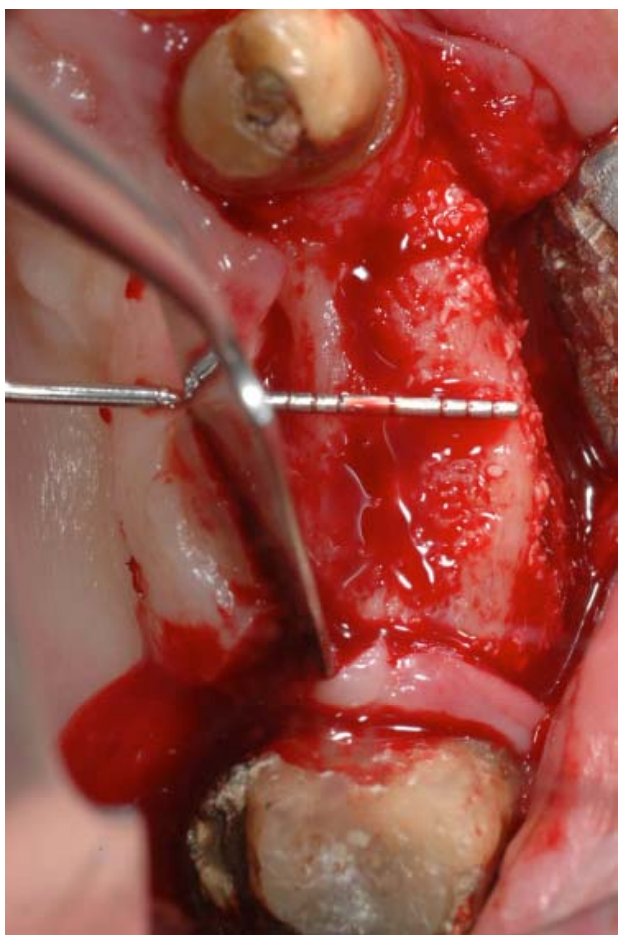

Fig. (5A). Occlusal view of the ridge at the stage of dental implant placement, 3 months after the surgery. The side test with the BioOss coverage.

and immediately after augmentation, by means of a periodontal probe.

On top of all onlay grafts, a thin layer of anorganic bovine bone granules was placed covering $50 \%$ of the block

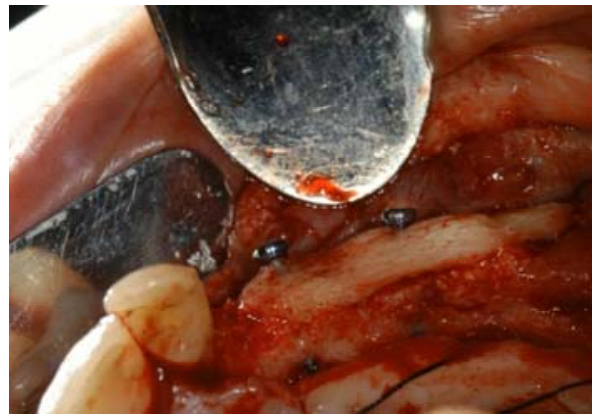

Fig. (5B). Occlusal view of the ridge at the stage of dental implant placement, 3 months after the surgery. The control test without BioOss coverage.

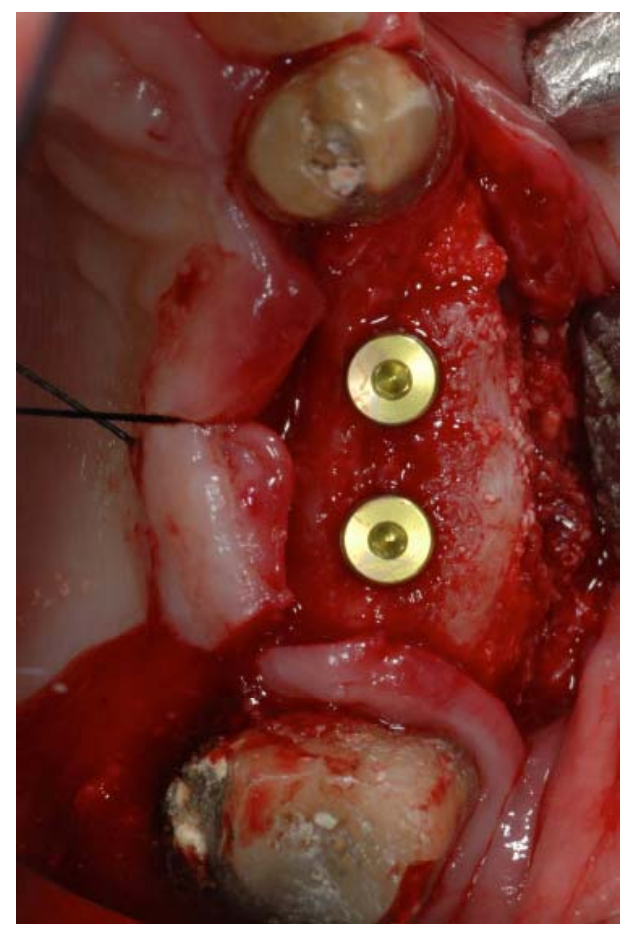

Fig. (6). Two dental implants placed on the recovered ridge.

extension (Fig. 5). The granules were kept in place by a collagen membrane. The other half of each onlay block remained untreated. Implants were placed after a healing period of three months. At the implant positioning stage the new bone ridge was about 8 to $10 \mathrm{~mm}$ increased on width.

After removing the fixation screws at the time of implantation, bone biopsies were taken at control and test sites with a trephine bur which was moved from buccal to palatal, to get cortical - and the underlying native cancellous bone.

At the time of the second surgery the test site clinically presented the fixation screws totally covered by bone, while the control site showed the head of the screws partially uncovered. Both sites underwent to dental implant positioning and then prosthesis was applied over (Figs. 6, 7).

\section{Histology and Histomorphometry}

All the histological examinations were perfomed at the Hard Tissue Research Laboratory, Department for Oral- and Maxillofacial Surgery, University Hospital, Freiburg, Germany. 


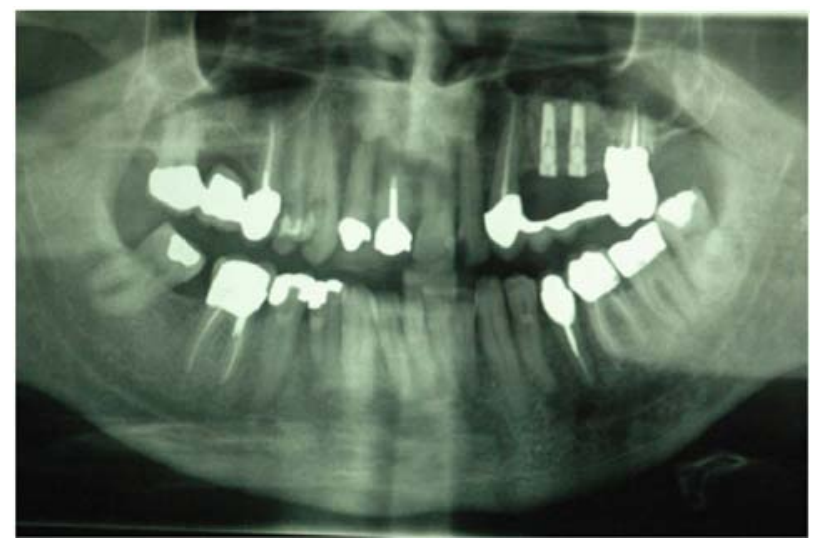

Fig. (7). Radiographic control of the two dental implants positioned.

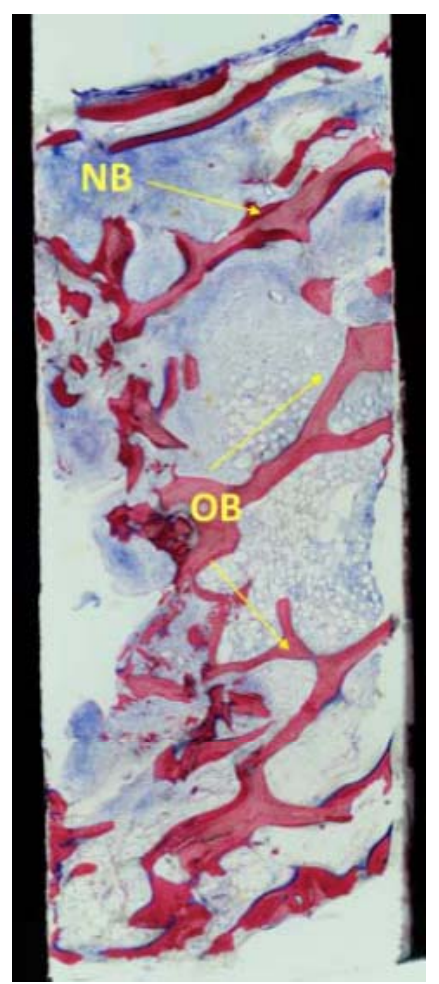

Fig. (8A). The histological findings show mature cancellous bone with predominantly lamellar structure. There are no signs of acute inflammatory reactions (original magnification x 50).

\section{Histologic Preparation}

Specimen were fixed in four per cent formaldehyde (Merck, Darmstadt, Germany) for one week and dehydrated using an increasing series of alcohol (70 - $100 \%$ ethanol) for one day with each concentration. Samples were resinembedded in Technovit 9100 (Heraeus Kulzer, Wehrheim, Germany) according to their specific protocol. After polymerization, specimen were cut in $300 \mu \mathrm{m}$ sections using a lowspeed rotary diamond saw Microslice TM (Metals Research, Cambrige, UK). These sections were mounted onto opaque acrylic-slides (Maertin, Freiburg, Germany) and grounded to a final thickness of approximately $60 \mu \mathrm{m}$ on a rotating grinding plate (Stuers, Ballerup, Denmark). Specimens were sub-

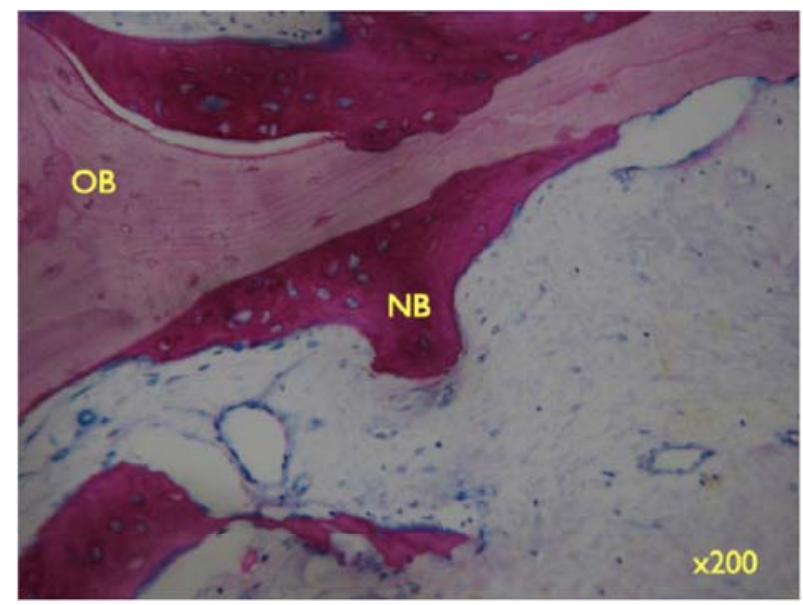

Fig. (8B). Higher magnifications unveil the bone structure, with new woven or lamellar bone deposited on older lamellar bone (x200).

sequently stained in azure II and pararosaniline (Merck, Darmstadt, Germany).

\section{Histomorphometric Evaluation}

Sample imaging was carried out with an Axio Imager M1 microscope equipped with a digital camera AxioCam HRc (Carl Zeiss, Göttingen, Germany). For histomorphometric purpose, the components of interest were digitally labeled. Green was attributed to biomaterial, yellow to older autologous bone and red to newly formed bone. Soft tissue is shown in the original colours of the histological staining procedure. Histomorphometric analysis of sections with BioOss coverage was performed with analySIS FIVE - software (Soft Imaging System, Münster, Germany).

\section{RESULTS}

\section{Clinical Evaluation}

All the patients had uneventful healing and were later successfully treated with dental implants in the regenerated areas.

\section{Histological Findings}

A) Specimens without Bio-Oss coverage: Onlay graft without Bio-Oss coverage; Pat. 1 - regio 14

The biopsy (Fig. 8a) shows mature cancellous bone with predominantly lamellar structure. Intertrabecular spaces are filled with connective tissue and bone marrow. Newly formed bone (NB- dark magenta) is added on top of older bone (OB-light magenta). There are no signs of acute inflammatory reactions (original magnification x 50).

Higher magnifications unveil the bone structure, with new woven or lamellar bone deposited on older lamellar bone (Fig. 8b, x 200; 8c, x 630).

B) Specimens with Bio-Oss coverage Onlay graft with Bio-Oss coverage; Pat. 1- regio 27.

Apart from mature cancellous bone, granules from the Bio-Oss coverage (BO) embedded in newly formed bone are present in the upper part of the biopsy (Fig. 9a). 


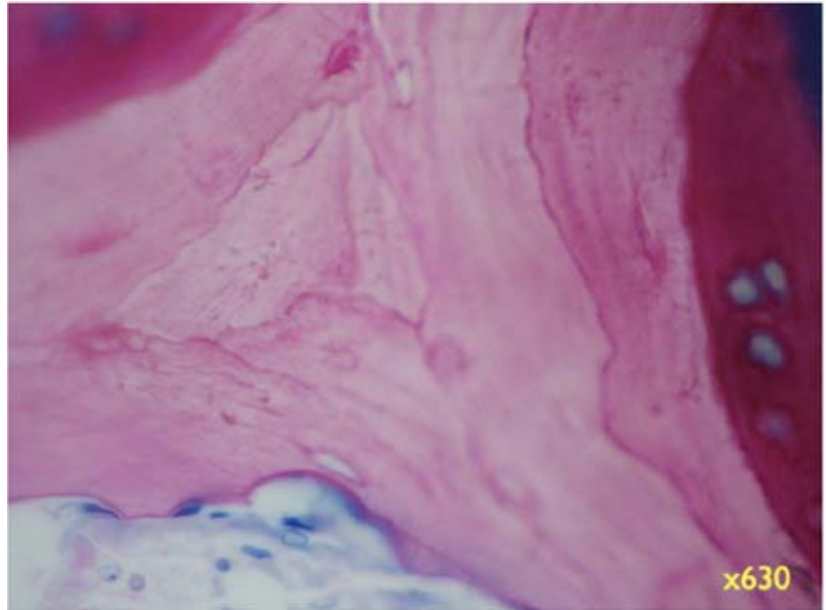

Fig. (8C). Higher magnifications unveil the bone structure, with new woven or lamellar bone deposited on older lamellar bone (x630).

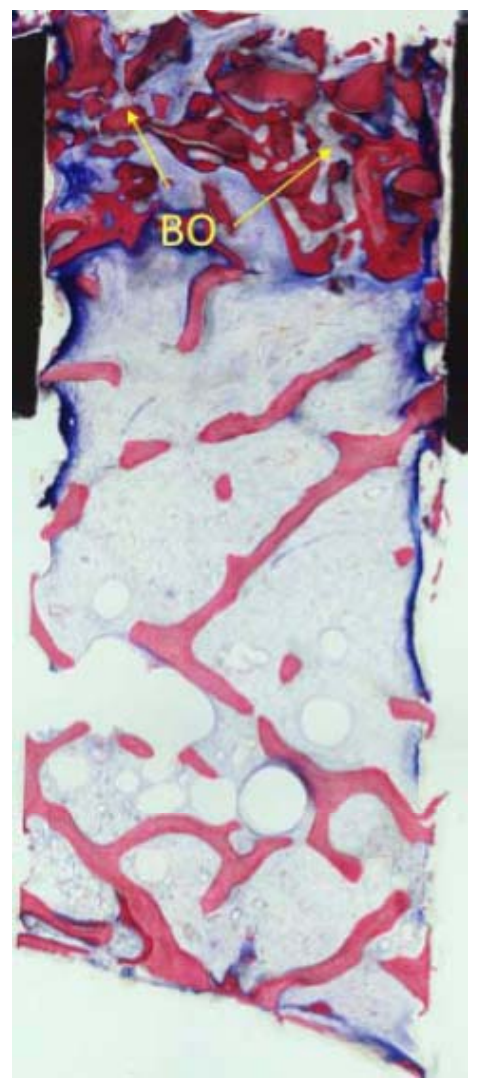

Fig. (9A). Part from mature cancellous bone, granules from the Bio-Oss coverage (BO) embedded in newly formed bone are present in the upper part of the biopsy.

For histomorphometric purposes (Fig. 9b), the components of interest were digitally labeled. Green was attributed to biomaterial, yellow to autologous older bone and red to newly formed bone. Soft tissue is shown in original colours of the histological staining procedure. A blue line limits the histomorphometric measuring field (original magnification $\mathrm{x}$ 50).

Histomorphometric analysis resulted in $19,3 \%$ new bone, $1,8 \%$ old bone, $26,5 \%$ Bio-Oss and $52,4 \%$ connective tissue.

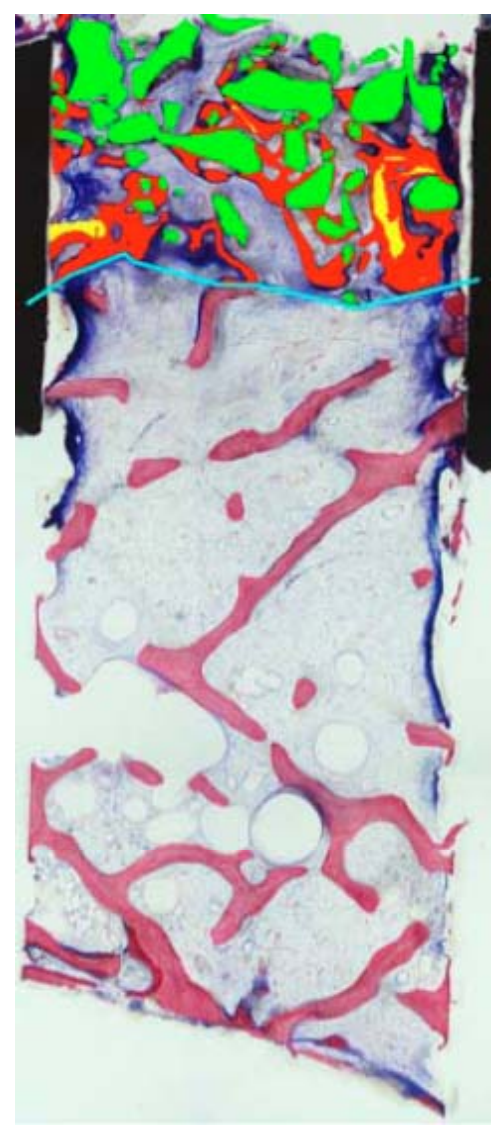

Fig. (9B). The components of interest were digitally labelled. Green was attributed to biomaterial, yellow to autologous older bone and red to newly formed bone. Soft tissue is shown in original colours of the histological staining procedure. A blue line limits the histomorphometric measuring field (original magnification x 50).

Therefore, the mineralized tissue fraction amounts to $47,6 \%$ in the area of interest.

Higher degrees of magnification show the deposition of newly formed bone (NB) on older bone (OB) and Bio-Oss particles (BO) (Fig. 9c, 9d: x 200). Seams of osteoblasts form Osteoid (OS) and deposit new bone on older lamellar bone (Fig. 9e: x 1000).

\section{DISCUSSION}

Several studies were undertaken to analyze bone resorption of autogenous block grafts used for oral and maxillofacial surgery. Verhoeven et al. [22] reported that in the first year after bone grafting, resorption is significant and may continue for years. Cortical bone grafts for example, may lose up to $33 \%$ of its strength during incorporation, and generally remodels over a 6 to 18 -month period. Fonseca et al. [23] also reported, that laying corticocancellous bone onto the mandibular buccal cortex for augmentation of the alveolar ridge is a poor method to change ridge morphological structure. Several parameters like embryological origin, architecture, orientation, and graft dimension have been suggested as reasons for the poor volume maintenance of the autogenous bone grafts.

Smith and Abramson [24] proposed two possible mechanisms for calvarial bone graft's volumetric superiority over iliac grafts. They compared calvarial - to iliac bone grafts 


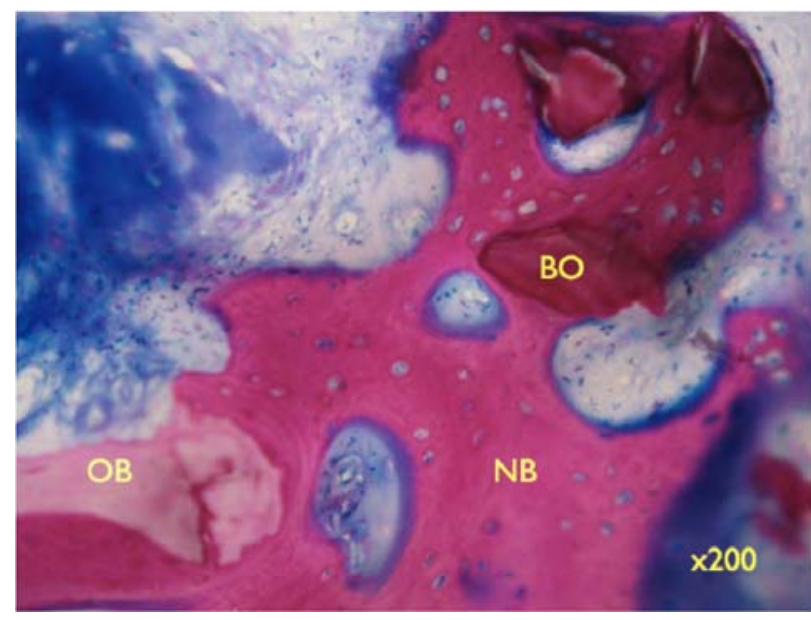

Fig. (9C). Higher degrees of magnification show the deposition of newly formed bone (NB) on older bone (OB) and Bio-Oss particles (BO).

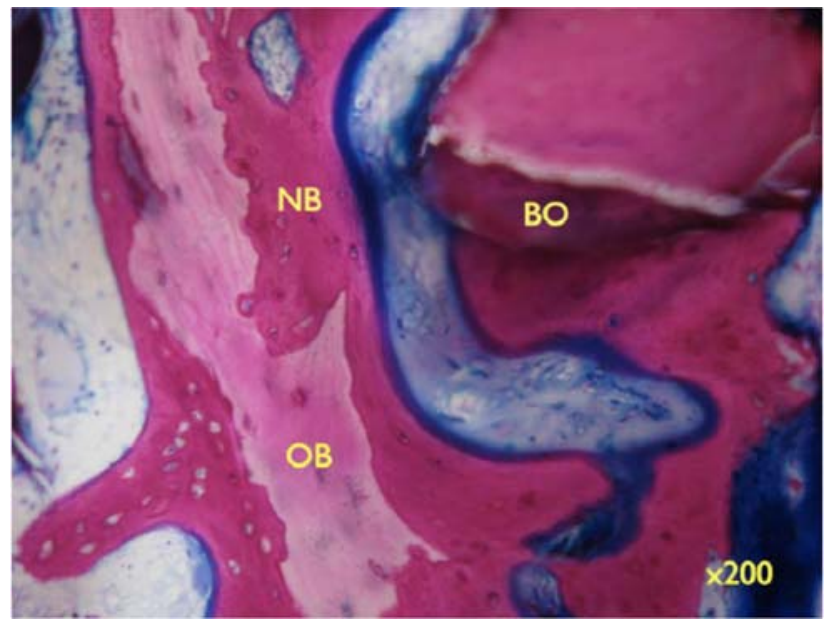

Fig. (9D). Higher degrees of magnification show the deposition of newly formed bone (NB) on older bone (OB) and Bio-Oss particles (BO) (x200).

using a rabbit model. After 1 year, the calvarial grafts had maintained their size and structure, while iliac grafts had lost at least $75 \%$ of their original volume. The authors concluded, that mechanical stress was a key factor for graft survival, believing that iliac bone required mechanical stress to maintain its morphology. After transplantation, loss of this stress led to resorption and poor volume maintenance, when compared to grafts from non-stress-bearing donor sites, such as calvarium. Authors [24] also hypothesized that the microarchitecture of the bone grafts could account for these differences, and noted, that iliac grafts had more cancellous bone than calvarial grafts, and that the increased cancellous component would lead to increased revascularization, resulting in increased resorption compared to calvarial bone graft.

Clinical studies have shown that use of calvarial bone is associated with low post-operative morbidity and a high success rate in bone augmentation procedures [25, 26]. Previous experimental studies indicated, that autogenous grafts with a more cortical microarchitecture, preserve the original bone

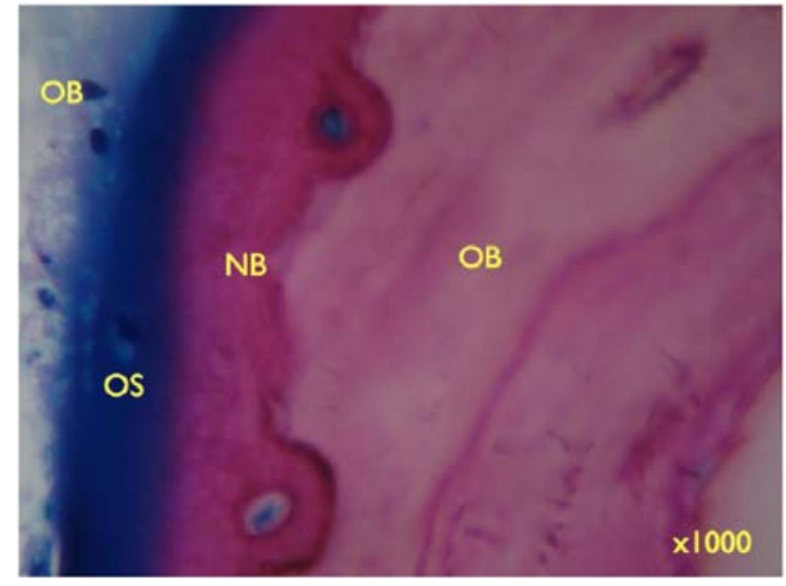

Fig. (9E). Seams of osteoblasts form Osteoid (OS) and deposit new bone on older lamellar bone (Figure 9e: x 1000).

volume more efficiently over time [27]. These findings suggest that grafts with different microarchitectures exhibit improved patterns of integration into the receptor bed. Comparative experimental studies between onlay grafts, obtained from the iliac crest and the calvarial, have shown that the latter preserves much higher levels of bone volume [28, 29, 30]. However the biomolecular reasons for such effects remain unknown.

Recently, Adeyemo et al. [31] published in 2008 an important microscopical and immunohistochemical study with a sheep model about the healing of onlay mandibular bone graft coverage with collagene membrane or bovine bone substitutes. The study showed that the effect of collagen membrane coverage on bone graft volume maintenance is dependent on membrane stability during healing and BioOss coverage of the bone graft. This was also associated with a remarkable increase in the volume of the augmented bone. These results also suggest that, late induction of apoptosis during development of the mature osteoblast phenotype. A differentiated osteocyte is an end point indicator of the bone remodeling process during bone graft healing.

Bio- Oss action has been reported to promote bone formation by alteration of osteoblast gene expression. Carinci et al. [32] identified genes that are differentially regulated in osteoblasts exposed to Bio-Oss. In an osteoblast-like cell line (MG-63) cultured with Bio-Oss, expression of several genes was significantly changed. These results could explain the reported bio affinity of BioOss for host animals, its biological affinity to osteogenic cells, and its capability to stimulate osteoblastic differentiation.

BioOss remodeling is divided in three different steps: firstly there is an integration with the surrounded bone; then a phase of resorption related to the osteoclasts action and finally a new bone formation when osteoblast cells substitute the BioOss granules with new woven bone [33, 34].

In general, the literature reveals the concerns of clinicians and researchers about the processes involved in the revascularization and maintenance of the volume of autogenous grafts obtained from different donor areas, as well as the influence of the microarchitecture and ossification type on these parameters [35-40]. 
It is believed, that autogenous bone grafts with a more cortical microarchitecture result in increased maintenance volume. Perforation or decorticalization of the receptor bed performed by many clinicians - aimed at facilitating graft revascularization, could increase osteogenesis and the graft incorporation rate [41, 42]. However, there are no records in the literature of onlay graft incorporation which correlate the biological events occurring within the graft with variations of volume and density and there are no histological analyses on human about how the graft resorption could be influenced and regulated.

\section{CONCLUSIONS}

The results of this investigation show, that the newly applied method led to complete healing and bone filling up to the desired volume. At sites without Bio-Oss coverage, partial exposure of the first threads of the fixation screws was observed, thus indicating that the remodeling process had led to cortical bone resorption. At sites treated with Bio-Oss coverage, no sign of bone resorption was observed, as stated by the absence of exposure of the fixation screws' threads. This result is in accordance with previous studies from Maiorana and co. [9, 12].

Bone volume maintenance at the test sites can be explained with the action of Bio-Oss, which is a slow - resorbing material, balancing the amount of autogenous bone reduction due to remodeling within the first three months after augmentation with a newly formed bone apposition. The effect of bone maintenance could evidenced by a clinical comparing of the volume of the sites treated with Bio-Oss coverage with the one in the control sites, in which the resorption is stated by the exposure of some threads of the fixation screws, at the moment of implant placement, 3 months after grafting.

Even though this study is presents only preliminary data, the clinical outcomes and the data given by Maiorana and co. in their previous studies, allow to postulate that Bio-Oss coverage technique is a reliable procedure for the volume preservation in onlay graft techniques.

\section{ACKNOWLEDGEMENT}

Authors want to thank Annette Lindner for the precious histological work and for her kind and professional cooperation.

\section{REFERENCES}

[1] Misch CM. Comparison of intraoral donor sites for onlay grafting prior to implant placement. Int J Oral Maxillofac Implants 1997; 12: 767-76.

[2] Fonseca RJ, Barber H, Frost DE, Zeitler DL, Stoelinga PJW. Osseous reconstruction. In: Fonseca \& Davis: Reconstruct Preprosthet Oral and Maxillofac Surg, Saunders WB, Ed. Philadelphia: 1995; 821-52.

[3] Santoro F, Maiorana C, Rabagliati M. Long-term results with autogenous onlay grafts in maxillary and mandibular atrophy. $\mathrm{J}$ Long Term Effects of Med Impl 1999; 9: 215-21.

[4] Augthun M, Yildirim M, Spiekermann H, Biesterfeld S. Healing of bone defects incombination with immediate implants using themembrane technique. Int J Oral Maxillofac Impl 1995; 10: 421-8.

[5] Buser D, Dula K, Hirt HP, Schenk RK. Lateral ridge augmentation using autografts and barrier membranes: a clinical study with 40partially edentulous patients. Int J Oral Maxillofac Surg 1996; 54: 420-32.
Chiapasco M, Abati S, Romeo E, Vogel G. Clinical outcome of autogenous bone blocks or guided bone regeneration with e-PTFE membranes for the reconstruction of narrow edentulous ridges. Clin Oral Impl Res 1999; 10: 278-88.

[7] Carpio L, Loza J, Lynch S, Genco R. Guided bone regeneration around endosseous implants with anorganic bovine bone mineral: a randomized controlled trial comparing bioabsorbable versus nonresorbable barriers. J Periodontol 2000; 71: 1743-9.

[8] Hämmerle CHF, Lang NP. Single stage surgery combining transmucosal implant placement with guided bone regeneration and bioresorbable materials. Clin Oral Impl Res 2001; 12: 9-18.

[9] Owens KW, Yukna RA. Collagen membrane resorption in dogs: a comparative study. Impl Dentist 2001; 10: 49-56.

[10] Zellin G, Gritli-Linde A, Linde A. Healing of mandibular defects with different biodegradable and non-biodegradable membranes: an experimental study in rats. Biomaterials 1995; 16: 601-9.

[11] Araujo MG, Sonohara M, Hayacibara R, Cardaropoli G, Lindhe J. Lateral ridge augmentation by the use of grafts comprised of autologous bone or a biomaterial: an experiment in the dog. J Clin Periodontol 2002; 29: 1122-31.

[12] Neukam FW. Oromandibular reconstruction with vascularized bone grafts in combination with implants. In Sailer HF: Oral and Maxillofacial Surgery, Clinic of North America, Saunders WB, Ed. Philadelphia 1994; 717-20

[13] Khoury F. Augmentation osseuse ant chirurgie implantaire: facteurs de pronostic. Implant 1999; 5: 221-37.

[14] Nystrom E, Ahlqvist J, Legrell PE, Kahnberg KE. Bone remodelling and implant success rate in the treatment of the severly resorbed maxilla: a 5 year longitudinal study. Int J Oral Maxillofac Surg 2002; 318: 158-64.

[15] Reinert S, Konig S, Bremerich A, Eufinger H, Krimmel M. Stability of bone grafting and placement of implants in the severely atrophic maxilla. Brit J Oral Maxillofac Surg 2003; 41: 249-55.

[16] Khoury F. Bone augmentation in oral implantology. Quintessence Books, Berlin: 2007; 197-200.

[17] Maiorana C, Beretta M, Salina S, Santoro F. Reduction of autogenous bone graft resorption by means of Bio-Oss coverage: a prospective study. Int J Period Rest Dent 2005; 1:19-25.

[18] Benezra Rosen V, Hobbs LW, Spector M. The ultrastructure of anorganic bovine bone and selected synthetic hydroxyapatites used as bone graft substitute materials. Biomaterials 2002; 23: 921-8.

[19] Peetz M. Charcaterization of xenogeneic bone material. In Philip Boyne Osseous reconstruction of the maxilla and the mandible. Quintessence Books, Chicago 1997; 87-100.

[20] Cawood J, Howell R. A classification of the edentulous jaw. Int J Oral Maxillofac Surg 1988; 17: 234-6.

[21] Misch CE, Judy KW. Classification of partially edentuolous arches for implant dentistry. Int J Oral Implantol 1987; 4: 7-12.

[22] Verhoeven JW, Ruijter J, Cune MS, Terlou M, Zoon M. Onlay grafts in combination with endosseous implants in severe mandibular atrophy: one year results of a prospective, quantitative radiological study. Clin Oral Implants Res 2000; 11: 583-94.

[23] Fonseca RJ, Clark PJ, Burkes EJ, Baker RD. Revascularization and healing of onlay particulate autogenous grafts in primates. J Oral Surg 1980; 38: 572-7.

[24] Smith JD, Abramson M. Membranous vs endochonral bone autografts. Arch Otolaryngol 1974; 99: 203-5.

[25] Lizukam T, Smolka W, Hallermann W, Mericske- Stern R. Extensive augmentation of the alveolar ridge using autogenous calvarial split bone grafts for dental rehabilitation. Clin Oral Impl Res 2004; 15: 607-15.

[26] Le Lorc'h-Bukiet I, Tulasne J-F, Llorens A, Lesclous P. Parietal bone as graft material for maxillary sinus floor elevation: structure and remodeling of the donor and of recipient sites. Clin Oral Impl Res 2005; 16: 244-9.

[27] Ozaki W, Buchman SR. Volume maintenance of onlay bone grafts in the craniofacial skeleton: micro-architecture versus embryologic origin. Plastic and Reconstruct Surg 1998; 102: 291-9.

[28] Hardesty RA, Marsh JL. Craniofacial onlay bone grafting: a prospective evaluation of graft morphology, orientation and embryonic origin. Plastic Reconstruct Surg 1990; 85: 5-14.

[29] Donovan CMG, Dickerson LNC, Hellstein MJW, Hanson MLJ. Autologous calvarial and iliac onlay bone grafts in miniature swine. J Oral Maxillofac Surg 1993; 51: 898-903.

[30] Chen NT, Glowacki J, Bucky LP, Hong HZ, Kim WK, Yaremchuk MJ. The roles of revascularization and resorption on endurance of 
craniofacial onlay bone grafts in the rabbit. Plastic Reconstruct Surg 1994; 93: 714-22.

[31] Adeyemo WL, Reuther T, Bloch W, et al. Healing of onlay mandibular bone graft covered with collagen mebrane or bovine bone substitutes: a microscopical and immunohistochemical study in the sheep. Int J Oral Maxillofac Surg 2008; 37: 651-9.

[32] Carinci F, Piattelli A, Degidi M, et al. Genetic effects of anorganic bovine bone (Bio-Oss1) on osteoblast-like MG-63 cells. Arch Oral Biol 2006; 51: 154-63.

[33] Boyne PJ. Comparison of porous and nonporous hydroxyapatite and anorganix xenografts in the restoration of alveolar ridges. In: Proc Symposium of the Amer Soc for Testing and Materials 1988; 369.

[34] Boyne PJ. Osseous reconstruction of the maxilla and the mandible. Chicago: Quintessence 1997; 13-20.

[35] Zins JE, Whitaker LA. Membranous versus endochondral bone: implications for craniofacial reconstruction. Plastic Reconstruct Surg 1983; 72: 778-85.

[36] Kusiak JF, Zins JE, Whitaker LA. The early revascularization of membranous bone. Plastic and Reconstruct Surg 1985; 76: 510-14.
[37] Lin KY, Bartlett SP, Yaremchuk MJ, Fallon M, Grossman RF, Whitaker LA. The effect of rigid fixation on the survival of onlay bone grafts: an experimental study. Plastic Reconstruct Surg 1990; 86: 449-56.

[38] Carvalho PSP, Vasconcellos LW, Pi J. Influence of bed preparation on the in corporation of autogenous bone grafts: a study in dogs. Int J Oral Maxillofac Impl 2000; 15: 565-70.

[39] Phillips JH, Rahn BA. Fixation effects on membranous and endochondral onlay bone graft revascularization and bone deposition. Plastic Reconstruct Surg 1990; 85: 891-6.

[40] Pinholt EM, Solheim E, Talsnes O, Larsen TB, Bang G, Kirkeby OJ. Revascularization of calvarial, mandibular, tibial, and iliac bone grafts in rats. Ann Plastic Surg 1994; 33: 193-7.

[41] Nishimura I, Shimizu Y, Ooya K. Effects of cortical bone perforation on experimental guided bone regeneration. Clinical Oral Implants Res 2004; 15: 293-300.

[42] Alberius P, Gordh M, Lindberg L, Johnell O. Onlay bone graft behavior after marrow exposure of the recipient rat skull bone. Scandinavian J Plastic Reconstruc Hand Surg 1996; 30: 257-66.

Received: August 08, 2010

(C) Maiorana et al.; Licensee Bentham Open.

This is an open access article licensed under the terms of the Creative Commons Attribution Non-Commercial License (http://creativecommons.org/licenses/by-nc/3.0/) which permits unrestricted, non-commercial use, distribution and reproduction in any medium, provided the work is properly cited. 